\title{
La sed, el fuego y la vida: una hermenéutica del protestantismo a través de Willis Hoover y Alberto Hurtado
}

\section{Thirst, fire and life: a hermeneutic of protestantism through Willis Hoover and Alberto Hurtado}

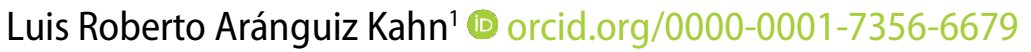

${ }^{1}$ Universidad de Chile, Centro de Estudios Judaicos, Santiago, Chile. Magíster en Estudios Internacionales, IDEAU. Santiago de Chile.

Irarangu@uc.cl

\section{(cc) BY}

\section{Resumen:}

El protestantismo en Chile ha sido objeto de creciente investigación, en especial por el movimiento pentecostal que es el grupo evangélico más grande del país. Sin embargo, la narrativa sobre los orígenes del movimiento no ha recibido el mismo grado de atención. Lo cierto es que, desde sus inicios, su tensión con otras formas de protestantismo ha sido una de las características más importantes que hizo posible su surgimiento. Al mismo tiempo, el crecimiento protestante en Chile significó un desafío para el catolicismo por su capacidad de misión en los sectores populares. Así, el protestantismo se vuelve objeto de reflexión tanto para pentecostales como para católicos. El presente artículo busca reflexionar comparativamente sobre dos relatos relevantes referidos al protestantismo en Chile, a saber, el libro Historia del avivamiento pentecostal en Chile de Willis Hoover, fundador de ese movimiento en el país, y las consideraciones sobre la expansión protestante en Chile por el Padre Alberto Hurtado en su obra ¿Es Chile un país católico? Desde un punto de vista hermenéutico, se buscará indagar en la así llamada "semántica profunda" de estos relatos para ilustrar el modo en que comprenden el protestantismo.

Palabras Clave: Sacerdotes chilenos; Protestantes en Chile siglo XX; Religión en Chile

\section{Abstract:}

Protestantism in Chile has been the subject of increasing research, especially the Pentecostal movement, which is the largest evangelical group in the country. However, the narrative about the origins of the movement has not received the same degree of attention. The truth is that since its beginnings, its tension with other forms of Protestantism has been one of the most important characteristics making its emergence possible. At the same time, the growth of Protestantism in Chile was a challenge for Catholicism due to its capacity for mission work in the popular sectors. Thus, Protestantism became an object of reflection for both Pentecostals and Catholics. This article seeks to reflect comparatively on two relevant accounts referring to Protestantism in Chile, namely, the book History of the Pentecostal Revival in Chile by Pastor Willis Hoover, founder of that movement in the country, and the considerations on the Protestant expansion in Chile by Fr. Alberto Hurtado in his book Is Chile a Catholic country? From a hermeneutical point of view, an attempt will be made to explore the so-called "deep semantics" of these writings to illustrate the way in which they understand Protestantism.

Keywords: Chilean priest; Protestants in Chile 20th century; Religion in Chile. 


\section{Introducción}

Willis Hoover (1858-1936) y Alberto Hurtado Cruchaga (1901-1952) son dos magnitudes de la historia religiosa de Chile, uno protestante y el otro católico. El primero fue un misionero metodista estadounidense que llegó a fines del siglo XIX y fue fundador del movimiento pentecostal chileno de 1909, mientras que el segundo fue un jesuita de tal relevancia que fue nombrado santo de la Iglesia Católica en el año 2005. Bien es cierto que la visibilidad pública de Hurtado es sobradamente mayor que la de Hoover, a este último no se lo conoce mucho más que entre los evangélicos o los investigadores. Sin embargo, no se puede comprender el origen del movimiento pentecostal, que tanto ha dado que hablar en las últimas décadas por su crecimiento demográfico y sus incursiones en la vida pública, sin él.

El protestantismo chileno empezó a ser estudiado sistemáticamente desde los años sesenta, siendo referencia obligada por entonces, y aún hasta hoy, el trabajo del sacerdote chileno Ignacio Vergara Tagle (1962), quien solía denominar al pentecostalismo como "protestantismo popular"; y el trabajo del sociólogo suizo comisionado para investigar el caso pentecostal por el Consejo Mundial de Iglesias, Christian Lalive d'Epinay (2009). Con los años ha sido creciente el número de investigaciones y aportaciones teóricas que se han hecho, principalmente en el campo de las ciencias sociales, para abordar este último movimiento (Mansilla, 2009) y, asimismo, podemos encontrar trabajos más recientes que lo investigan con un enfoque histórico (Orellana Urtubia, 2006) y en el marco general del protestantismo (Sepúlveda González, 1999). Estos solo son algunos ejemplos de los diversos desarrollos que ha habido en el campo. Pese a ello, la figura de Willis Hoover no ha recibido una atención pormenorizada. Ciertamente, su obra Historia del avivamiento pentecostal en Chile otorga una serie de datos informativos que permiten reconstruir las manifestaciones carismáticas, así como el proceso de separación entre el movimiento pentecostal y la Iglesia Metodista. No obstante, consideramos aquí que también entrega una cantidad de información valiosa para adentrarse en los intersticios de la construcción del gran relato que dio sustento al movimiento $y$, sobre todo, respecto a su autocomprensión en el marco del protestantismo.

El libro Historia del avivamiento pentecostal en Chile fue publicado en 1931, aunque los fragmentos que lo componen venían siendo publicados en las revistas Chile Pentecostal y Fuego de Pentecostés ya desde 1926. Por su parte, el libro ¿Es Chile un país católico? de Alberto Hurtado fue publicado en 1941, diez años después. En ambos casos, estamos frente no a tratados teológicos, aun cuando se habla de teología. Tampoco estamos ante libros de historia ajustados a los rigores de la disciplina historiográfica, aun cuando refieren a cuestiones históricas. Se trata de obras de un carácter más personal, en el sentido de que no pretenden satisfacer criterio alguno de validez académica, sino que se presentan como la memoria de una experiencia religiosa y comunitaria en un caso, y como un estudio o reflexión de época en el otro. El hecho de que ambos textos compartan 
este carácter personal permite evaluarlos como relatos religiosos. Este término 'relato' no implica en modo alguno una degradación de la seriedad o validez de estos textos. Por el contrario, los ordena como un modo específico de producción intelectual en el campo del pensamiento religioso. Los autores se toman la libertad de elaborar reflexiones que, utilizando diversos recursos semióticos, construyen un imaginario específico sobre el tema que trabajan.

Así, la propuesta de este artículo consiste en mostrar cómo, desde un punto de vista hermenéutico, Willis Hoover y Alberto Hurtado elaboran un imaginario respecto al protestantismo, uno en relación con la variante pentecostal, y otro en relación con el catolicismo. El hecho de que, ambos textos, son escritos con una distancia cronológica de solo una década los hace contextualmente cercanos y esto, así como la diferencia de procedencias religiosas, hace tanto más interesante la comparación de ambos textos.

\section{Elementos teóricos para la interpretación semiótica de textos religiosos}

Los textos que están ante nosotros se constituyen en objeto de estudio y lo que se propone este artículo es realizar una suerte de análisis o crítica literaria. Pero la naturaleza de nuestros textos no es la de una narración de ficción o de producción poética, sino la de relatos religiosos. Pese a que esta diferencia puede presentarse como un obstáculo, el crítico literario Harold Bloom (2009) ha propuesto establecer una analogía entre crítica literaria y crítica de la religión. En su libro La religión americana sostiene que, así como la crítica literaria se realiza mediante el examen de la dimensión irreductible de la estética en el arte literario, "la crítica de la religión debe buscar la dimensión espiritual irreductible que hay en las cuestiones religiosas" (p. 17). Ahora bien, esto que compete al análisis, se sujeta a una analogía aún más primordial, porque religión y literatura no solo pueden ser objetos de análisis, sino que ambos comparten una característica semejante. En efecto, según Bloom (2009),

...el deseo creativo y el deseo religioso tienen más en común entre ellos que ninguno de los dos con Eros. El carácter poético, tal como yo lo entiendo, se origina en una rebelión contra la muerte, y también en el convencimiento de que sus orígenes no son naturales y se remontan a un abismo que precede la existencia del mundo (p. 37)

El carácter rebelde contra la muerte de la poesía y la religión se cifra en la incomprensión que esta produce cuando se está convencido de un origen primordial, que excede la existencia natural. Por eso, la religión "surge de nuestra percepción de la muerte. Darle un sentido a la falta de sentido es la interminable búsqueda de la religión" (Bloom, 2009, p. 26). Toda religión, como toda poesía, busca lo que los analistas de la religión llamarían "trascendencia", un "misterio" que se esconde en un más allá de lo humano (Croatto, 2002). Y, sin embargo, esto indecible necesita ser dicho por quién lo ha experimentado. Para eso, se crean lenguajes por los cuales se expresan las experiencias religiosas, del tipo que sean, y dicha expresión 
...es tanto comunicación de lo vivido, cuanto nueva vivencia en el acto mismo de ser dicha. Cada uno de los lenguajes de esa vivencia -el símbolo, el mito, el rito, la tradición convertida en textola recrea a su manera, pero todos participan de esa cualidad (Croatto, 2002, p. 62)

El lenguaje religioso está cargado de significaciones que escapan a la superficialidad de la referencia, como ocurre en el uso convencional de una lengua. Existe ahí una "imaginación poética" (Giraud, 1972, p. 94) que utiliza una serie de recursos semióticos, tanto lingüísticos como no lingüísticos. Figuras literarias, imágenes, formas, todo apunta a una significación más profunda que busca expresar un sentido de trascendencia. En particular, destaca en nuestros casos el uso de la metáfora. Este recurso será entendido, para estos efectos, como la "equivalencia" o "semejanza entre dos sujetos" (Croatto, 2002, p. 68).

Además de tener en cuenta lo anterior, un ejercicio de crítica de la religión necesita distinguir entre la experiencia religiosa y la teología. De hecho, tal como sugiere Bloom (2009), su tarea consiste precisamente en adentrarse en esa diferencia: "construir puentes allí donde hay un vacío, explicar, en concreto, las curiosísimas relaciones que por lo general imperan entre la teología y la experiencia religiosa real, en cualquier fe" (p. 32). Pero también es necesario tener en cuenta otra distinción. Al acercarse al plano de lo religioso en general, puede suponerse que la crítica de la religión ha de ser simplemente crítica de las instituciones religiosas. Pero no es eso a lo que se apunta si lo religioso es analógico a lo poético; su sustancia es más profunda que las dinámicas sociales, las configuraciones institucionales, las prácticas comunitarias, etc. El núcleo, el elemento irreductible tiene que ver con "lo divino".

De acuerdo a Henri Meschonnic, teórico del lenguaje, lo religioso es la socialización, ritualización o mas bien la "gestión de lo divino" (Meschonnic, 2007, p. 163), una forma posterior y distinta de lo divino. En este sentido, analizar lo religioso podría llevar eventualmente al elemento irreductible, porque se genera a partir de él, pero aquello no implica en modo alguno que le sea siquiera semejante. Lo divino, pensando en el Génesis, es "el principio de vida que crea a todas las criaturas vivientes" (Meschonnic, 2007, p. 162) y, más aún, "una trascendencia absoluta, respecto a lo humano, de la potencia creadora de la vida" (Meschonnic, 2007, p. 162). Lo divino apela siempre a un poder sobrehumano, que en el caso de los cristianos equivale a las personas de la trinidad, a la trinidad misma $y$, lo que se supone elemental es que el ser humano puede, fe mediante, tener contacto personal con esa divinidad. Este es el núcleo, el elemento irreductible del cristianismo.

Ahora bien, ¿cómo ha de encontrarse esto en dos textos que no son poesía mística ni cristiana ni profana, pero que tampoco son tratados de teología mística o de teología en general? Naturalmente, se requiere de un ejercicio de interpretación. Para llevar a cabo esto último, es necesario tener en cuenta algunas cosas. En primer lugar, el hecho de que toda interpretación se hace de modo unilateral, la coloca en el lugar de una conjetura. El texto como ejemplifica Paul Ricœur (2011), es un objeto mirado siempre desde una posición, y por lo tanto diríamos, no de otra. 
En segundo lugar, hablar de interpretación requiere distinguir entre un enfoque estructuralista y uno hermenéutico. El primero, cuyo paradigma son las ciencias naturales - ¿y por qué no las sociales? -, trata de explicar los fenómenos externos, observables, mientras que el segundo trata de comprender la experiencia de otros sujetos. Así, podría decirse que el objeto pentecostalismo chileno ha sido explicado, pero no necesariamente comprendido. El texto tiene un significado que no se resuelve solo en función de sus elementos interiores y para ellos, sino también una referencialidad que apela a una comprensión de la experiencia de otros sujetos (Ricœur, 2011, p. 84). Interpretar no es explicar sino, ante todo, comprender. Todo texto puede explicarse, y ello se logra mediante un análisis superficial. Sin embargo, para comprenderse, ha de buscarse una "semántica profunda" (Ricœur, 2011, p. 99), puesto que los textos, y en especial los míticos y religiosos, apuntan a algo fuera de ellos, su capacidad de significado no queda sujeta solamente a su propia completitud como objeto.

Dado que pondremos atención al uso de la metáfora, cabría también notar cómo piensa Ricœur que es conveniente entenderla en el proceso de interpretación. Si bien comparte el hecho de que la metáfora opera como una asociación de semejanza como Croatto (2002), también sostiene que amplía el sentido de lo que semeja porque resuelve un enigma, una "disonancia semántica" (Ricœur, 2011 p. 65). Es decir, se trata de un mecanismo que permite ampliar el entendimiento sobre algo y, por ello, ofrece nueva información. Aplicado esto al lenguaje religioso, cuyo objeto siempre es todo lo relacionado con el campo de lo trascendente, la metáfora de un lenguaje religioso es una forma de ampliar el conocimiento respecto a todo lo relacionado con ese campo.

La elaboración de obras, como las que hemos seleccionado, responde al hecho de que "a través de la narración el sujeto "modela" una experiencia real o imaginaria" (Klein, 2007, p. 14) y busca una forma de escritura que se ajuste a su propósito. Para un autor, el género es el de un relato histórico, para otro es una suerte de genero ensayístico. En ambos casos, "es a partir de la narración (...) que un sujeto o una comunidad puede dar cuenta de sus orígenes y de su historia para inscribirse en la memoria y resistir el olvido" (Klein, 2007, p. 15). Hoover no puede no escribir como pentecostal, Hurtado no puede no escribir como católico, no porque estén privados de la facultad para hacerlo, sino porque el propósito de su tema es precisamente dirigirse a sus comunidades. Uno narra un origen e historia y deja con ello plasmada una identidad religiosa común, otro narra la respuesta a una pregunta existencial de su comunidad religiosa. Huelga decir que no se cree aquí que los textos contengan en modo alguno todo lo que se requiere para comprender las múltiples dimensiones de lo religioso, pero si contienen información que puede ayudar a adentrarnos en esos dominios.

Nuestra tarea como críticos religiosos es develar el sentido, la semántica profunda, el elemento irreductible del caso religioso. Si consideramos que este elemento puede estar expresado de algún modo en los textos, entonces nuestra tarea hermenéutica es dar con él, puesto que de ese modo podremos comprender mejor el fenómeno. Por lo tanto, debemos responder a la pregunta 
¿cuál es el elemento espiritual esencial que está tras este fenómeno religioso y cómo aparece expresado en estos textos?

\section{El pastor Hoover, o el fuego del Espíritu}

Aunque es cierto que el pentecostalismo logró en Chile una fuerte adherencia en los sectores populares, su forjador principal no era de esa extracción. Willis Hoover venía de una familia acomodada de Estados Unidos, era médico, y su celo misionero le impulsó a explorar suelo latinoamericano. Estando ya en Chile, cursó estudios teológicos y, en 1902, fundó el Seminario Bíblico Evangélico de la Iglesia Metodista Episcopal y fue su presidente desde 1904 hasta 1908 (Snow, 1999), además de haber sido profesor y rector del colegio lquique English College. Se está frente a un autor con una formación que le permitía comprender las coordenadas de debates propios de la época.

El libro del pastor Willis Hoover contiene una serie de descripciones que son útiles para comprender el origen de varias prácticas culticas pentecostales. Ellas suelen ser mencionadas en investigaciones, pero, a diferencia del pasado, hoy también pueden encontrarse descritas incluso con lujoso detalle en la literatura de ficción (Rivera Letelier, 2006), y hasta han sido objeto de ridiculización en programas de televisión. Glosolalia -el hablar en lenguas-, profecías, el dar tres glorias a Dios, risa espiritual, éxtasis, entre varias otras experiencias, fueron asumidas como un modo de manifestación del Espíritu Santo por esos días entre los pentecostales. También, y cuanto más distintivo del movimiento, son las manifestaciones referidas al cambio radical de comportamiento de las personas, lo que usualmente se denomina "conversión". Y aquí tenemos un primer elemento que orientará nuestra interpretación. Es en el lenguaje religioso del autor que todos estos hechos son descritos como "manifestaciones". Y una manifestación, por su propio significado, es la forma de presentarse de algo más. En este caso, tales experiencias son el resultado de la acción de un otro, de Dios, el Espíritu Santo y algunas de ellas son prueba de la experiencia espiritual más distintiva del pentecostalismo, usualmente llamada "bautismo de fuego" del Espíritu (Dayton, 2008; Hoover, 1984). A estos hechos se les llamó "avivamiento". Esta expresión no es infrecuente en sectores protestantes y, por lo general, se la utiliza para designar un impulso renovador. Semánticamente, el término remite a la "vida". Su significado metafórico elemental es que, por acción divina, los cristianos reciben un incentivo espiritual. El avivamiento pentecostal se distingue de otros precisamente por las "manifestaciones" extrañas al protestantismo de la época. Por lo tanto, todas esas descripciones del pastor Hoover son útiles solo en la medida que remiten a otro elemento que origina estas expresiones observables. En este sentido, el relato tras este texto no son las manifestaciones, tampoco es en sí mismo el quiebre del movimiento pentecostal con la Iglesia Metodista -que también es una consecuencia indirecta de la acción de aquel otro-. 
La hipótesis nuestra es que el elemento irreductible, la semántica profunda a la que nos remite este texto, es al problema de la acción milagrosa de Dios al interior del protestantismo. De hecho, tal como vimos antes, este es un caso preclaro en el que se evidencia la diferencia que puede llegar a haber entre una teología y una experiencia religiosa (Bloom, 2009).

Al comienzo del libro, Hoover (1984) relata que, en 1902, encontrándose en un estudio sobre el libro de los Hechos de los apóstoles, un feligrés le preguntó "¿Qué impide que nosotros seamos con esta iglesia primitiva?" (p. 10), refiriéndose con ello específicamente a la posibilidad de que los creyentes tuviesen experiencias espirituales milagrosas. Naturalmente, este deseo por volver a la iglesia primitiva no es propiedad de los pentecostales. Harold Bloom (2009) nos recuerda que el mito de la religión americana es justamente "la restauración de la iglesia primitiva" (p. 38). Conflictiva pregunta, no para Hoover, quien consideraba que era algo posible, sino para el contexto eclesial en el que se desenvolvía.

Las manifestaciones espirituales que comenzaron a ocurrir dejaron en evidencia una cuestión capital: que en las filas metodistas había quienes se rehusaban terminantemente a asignarles un valor divino y, por tanto, no creían en ellas. Más claramente, no creían que tras ellas estuviese la operación del Espíritu Santo. El relato del pastor empieza a acentuar la descripción de esta oposición que, en última instancia, era eminentemente teológica. Por ejemplo, Hoover (1984) cuestiona que en su tiempo hubiese personas en el metodismo que enseñaban que "Jesús era tan hombre que adorarlo es idolatría" (p. 92), que "Juan fabrica el apocalipsis con su imaginación" (Hoover, 1984, p. 92) y que no es posible que Dios revele aspectos de la vida venidera; o que "el libro de Jonás es un cuento" (Hoover, 1984, p. 92) y que es comparable con otras piezas de literatura. Como estos ejemplos, Hoover (1984) provee varios más en su libro. No obstante, advierte prontamente el problema teológico tras ellos, señalando: “¿Qué se puede decir de una iglesia cuyos seminarios emiten tales enseñanzas y cuyos periódicos las propagan? Estos son los frutos de la alta crítica y el modernismo que hoy día dominan en universidades, seminarios e iglesias" (p. 92).

Puede notarse que estamos ante dos problemas. El primero de ellos es el creer o no en las manifestaciones espirituales. Pero el segundo es el creer o no creer en las afirmaciones de la Biblia. La distinción entre ambas dimensiones no es clara en el relato. Tal es así que, podría llegar a sugerirse desde el texto que quienes se oponían a las manifestaciones, lo hacían por incredulidad, pero que dicha incredulidad estaba a su vez enraizada en una desconfianza en la Biblia que se debía a la influencia de la alta crítica y el modernismo. Lógicamente, si la Biblia no era confiable, entonces los hechos narrados en el libro de los Hechos de los apóstoles tampoco. Por lo tanto, era teológicamente inconcebible que situaciones como aquellas pudiesen ocurrir diecinueve siglos después. 
Hoover no sitúa a estas expresiones de desconfianza como un problema en sí mismas, sino como la consecuencia de algo más, que es la presencia de las ideas de "la alta crítica y el modernismo" en las instituciones metodistas. La alta crítica y el modernismo son las tendencias que llevan a que incluso las autoridades del metodismo acaben por enseñar que, por ejemplo, el libro de Jonás no es más que una cuento o fábula. Su oposición, por tanto, no es solo a la afirmación como tal, sino a las raíces teológicas que la hacen posible. Esto implica que el pastor Hoover entiende que hay una tendencia teológica que lleva a negar elementos importantes de la Biblia y que él a su vez hace su crítica adoptando una posición teológica contraria a aquella modernista.

Prestemos atención a otra afirmación de Hoover (1984):

Sólo hace poco que en mi la Palabra de Dios está hallando su libertad de las ataduras a las que estaba sujeta, debido a las sombras que las interpretaciones modernas la acechaban; las que, aunque no niegan abiertamente que un ángel apareció a Pablo, que Pedro vio un vaso como un gran lienzo, etc., se acercan tanto a esa negación que se siente que están buscando disculpa por la condición de la mente de esas personas, de tal manera que uno casi siente vergüenza de decir francamente 'Yo creo exactamente aquello' (p. 77)

Nuevamente aparece aquí una crítica a las "interpretaciones modernas", las mismas que le permitían a un pastor, escribe Hoover (1984) con preocupación, sostener que el Apocalipsis es "una fábula, no más" (p. 78) y que el Antiguo Testamento "no era de ninguna autoridad" (p. 78). A tal punto llegaba esta tensión teológica que el pastor de Valparaíso llegó a afirmar que "hasta donde puedo entender, estoy combatiendo a todas las doctrinas falsas" (Hoover, 1984, p. 79), como si se tratara de una guerra. Decían los incrédulos sobre las manifestaciones que "la Biblia y la razón no tienen lugar" (Hoover, 1984, p. 79) y viendo Hoover (1984) que ellos mismos no creían en las enseñanzas bíblicas contestaba "no todo lo 'anti-bíblico' está en la persona del acusado" (p. 79). Como se ve, el objeto de discusión pasa de ser la creencia en las manifestaciones carismáticas, a ser la creencia en la Biblia. Ambos sectores se acusan de estar reñidos con la Biblia: uno por tener experiencias religiosas que parecen reñidas con ella; y otro por no creer en absoluto en la validez de sus enseñanzas. Pero claramente, no podían los dos sectores tener razón.

¿Qué era lo que estaba en juego? Aunque no precisa a qué se refiere con "alta crítica" y con "modernismo", lo cierto es que una mirada a la historia de la teología del siglo XIX ofrece una perspectiva más clara de este problema. En los días de la Reforma Protestante del siglo XVI, se redactaron numerosos textos doctrinales que iban a afirmar los cimientos de la teología protestante en contraposición a la teología católica a la cual tan ardientemente desafiaban los reformadores europeos. Así, aparecieron documentos confesionales luteranos, reformados, entre varios más. A partir de estos documentos se inició toda una reflexión teológica que buscó su fundamento en las enseñanzas bíblicas, así como en las formulaciones doctrinales históricas del cristianismo. En ese sentido, los reformadores protestantes estuvieron de acuerdo con las doctrinas históricas del cristianismo como la trinidad y la cristología, entre tantas otras. 
Juan Wesley, fundador del movimiento metodista en el siglo XVIII, también iba a estar de acuerdo en los temas fundamentales. Como ministro anglicano, adhería a las formulaciones doctrinales de su iglesia y si bien no las aceptaba todas, conservó las que consideró más importantes. Por ello, de los 39 artículos de la fe anglicanos, conservó 25 para su movimiento. Willis Hoover (1984), resistiendo a las críticas, declaraba "estudiaré y enseñaré a Wesley y la Biblia. No tengo doctrinas nuevas" (p. 72), colocándose así del lado de la tradición wesleyana y de una adherencia ortodoxa, esto es, no "moderna", a la Biblia. En términos teológicos, lo que estaba afirmando era que se mantendría leal a las creencias cristianas fundamentales. Por eso es que no podía admitir que, en el movimiento iniciado por el propio Wesley, se pusieran en cuestión dichas creencias.

Al cuestionar al "modernismo" y la "alta crítica", está refiriéndose Hoover a lo que se conoce convencionalmente como "teología liberal". Son varias las ideas y teólogos que la promovieron desde distintos enfoques, pero lo que todos tienen en común, y que permite agruparlos, es que interrogaron algunos aspectos fundamentales de la fe cristiana tradicional. Ni por mucho fue el pentecostalismo el único movimiento que reaccionó a esta corriente. También surgió, por ejemplo, la contrapropuesta ortodoxa desde el presbiterianismo estadounidense, siendo paradigmático el caso del pastor Gresham Machen (1881-1937), quien publicó en 1923 un libro titulado Cristianismo y liberalismo en el cual sostuvo, entre otras cosas, que

El intento liberal de reconciliar al cristianismo con la ciencia moderna realmente ha renunciado a todo lo distintivo del cristianismo, al grado que los residuos son en lo esencial aquel mismo tipo indefinido de aspiración religiosa que existía en el mundo antes de que el cristianismo apareciera en escena. Al intentar eliminar del cristianismo todo lo que en nombre de la ciencia pudiera ser objetable, al intentar sobornar al enemigo con aquellas concesiones que el enemigo desea ardientemente, el apologista en realidad ya ha abandonado lo que empezó a defender (Machen, 2013, p. 29)

Nada distinto de esto es lo que pensaba Hoover. Machen, pastor y teólogo, pertenecía a la Iglesia Presbiteriana en los Estados Unidos de América (Presbyterian Church in the United States of America, PCUSA), que en los primeros años del siglo XX mostró una abierta adherencia a las orientaciones de la teología liberal en su seminario, por lo cual se opuso férreamente. De aquí surgió la creación del Seminario Teológico de Westminster en 1929, de orientación teológica y doctrinal ortodoxa lo que, junto con otras fricciones al interior de la PCUSA, acabó en la expulsión de Machen y sus adherentes quienes crearon luego la Iglesia Presbiteriana Ortodoxa (Orthodox Presbyterian Church, OPC). Es decir, Machen al igual que Hoover, también acabó separándose de su iglesia de origen. La diferencia es que en este caso la separación ocurrió exclusivamente respecto al plano teológico, en torno a la tensión entre ortodoxia y liberalismo. En cambio, en el caso pentecostal el componente añadido fue la experiencia espiritual. En otros términos, la gran diferencia entre el movimiento presbiteriano ortodoxo y el pentecostal es que una acentuó la dimensión doctrinal de la fe, mientras que el otro su dimensión sensible. 
La teología liberal, si bien encuentra su raíz en un desarrollo histórico de mayor longitud, se formula como tal en el siglo XIX. Aunque no es el propósito de este trabajo hacer historia de la teología, conviene recoger una descripción más precisa para adentrarnos más en el problema. Veamos lo que señala un teólogo católico al respecto:

La teología protestante del siglo XIX se caracteriza por la utilización a gran escala en las ciencias sagradas del método histórico-critico. En ella se deja sentir poderosamente el influjo del racionalismo, para el que las narraciones bíblicas y los fenómenos religiosos se reducen a una experiencia subjetiva de orden natural (García Gómez-Heras, 1972, p. 164)

Encontramos aquí varios elementos de interés. En primer lugar, que la teología protestante del siglo XIX es influida por el racionalismo, una tendencia intelectual que considera a la razón del ser humano como el fundamento del conocimiento. En este marco, la "revelación" (por ejemplo, las Escrituras), como fuente de conocimiento resulta inadmisible y por ello se opta por hablar de "fenómeno religioso", el cual de todos modos es de orden natural y, por tanto, no sobrenatural. La desconfianza en cualquier manifestación atribuida a un origen sobrenatural queda así resguardada. En segundo lugar, encontramos la alusión al "método histórico-critico" que no es otra cosa que la "alta crítica" a la que aludía Hoover. ¿En qué consiste? Nuestro autor católico lo aclara así:

La aplicación de la crítica histórica al análisis del texto sagrado puso al descubierto la heterogeneidad de las fuentes empleadas en él y su interdependencia con las literaturas contemporáneas. En una palabra: su dimensión humana. La manipulación de la Sagrada Escritura como un libro más hizo perder en muchos la conciencia de su peculiaridad y puso sobre el tapete la angustiosa pregunta de la existencia de una Palabra de Dios, de una revelación divina en la Biblia. Esta cuestión se agudizó sobre todo cuando llegó el momento de utilizar los resultados de la crítica histórica en la reconstrucción de la existencia humano-divina de Cristo (García Gómez-Heras, 1972, p. 164)

En suma, el "modernismo" que denunciaba Hoover (1984) al interior del metodismo, en las más diversas expresiones que le disgustaban, remitía a este movimiento teológico del siglo XIX que, podría decirse, "naturalizó" lo sobrenatural del cristianismo, despojando al texto sagrado de su carácter revelado para analizarlo como cualquier obra literaria o histórica. Bien es cierto que en dicho texto hay elementos pertenecientes a los géneros literario e histórico. Pero lo que estaba en cuestión en esos días no era si acaso en la Biblia podían o no encontrarse esos elementos sino, sobre todo, si esos elementos podían finalmente demostrar que la Biblia no era creíble y, en suma, que era un producto simplemente humano y no revelación divina. Si el metodismo liberal del tiempo de Hoover también enseñaba la Biblia, ¿por qué habría tomado tanta distancia? Porque el problema no era la Biblia, sino el modo radicalmente distinto en el que él la entendía desde su posición ortodoxa alineada la teología tradicional, y el modo en que la veía el metodismo influenciado por las tendencias liberales.

Ahora bien, Hoover no veía a la teología liberal como un riesgo únicamente dentro del metodismo. Por el contrario, desarrolla toda una teoría de la historia del cristianismo en la cual el pentecostalismo viene a ocupar un destacado lugar. Desde su punto de vista, "la generalidad de las 
iglesias evangélicas" está atravesada por estas corrientes de incredulidad como las liberales y es por eso que considera que el pentecostalismo viene a ser una fuerza de oposición, ya no simplemente contra el "mundo" o la sociedad secular, sino contra las propias iglesias protestantes. Tal es así que considera que "De los valdenses, luteranos, presbiterianos, metodistas, salvacionistas y otras muchas que así han salido del seno de la iglesia para formar otra más pura, nosotros los pentecostales son los últimos hasta la fecha" (Hoover, 1984, p. 96). La metáfora de la pureza se vuelve aquí relevante. Su opuesto es la impureza. En el lenguaje religioso, lo puro es lo santo, es decir, apartado de lo profano.

Si el protestantismo, que es el movimiento que surgió precisamente contra la corrupción de la Iglesia Católica, se ha corrompido, entonces es necesario que aparezca un nuevo movimiento. Es de este modo que Hoover ubica al pentecostalismo no como una reacción al protestantismo y sus ideas, con las cuales concuerda, sino una reacción contra el liberalismo que ha minado la fe protestante. En sus términos,

Cada nueva iglesia que se formó, fue por la decadencia e infidelidad de la que ya existía, y fue por causa de profundas convicciones de necesidad de ser más fieles y mas puros que motivó su formación. De aquí resulta que las más antiguas en general son las más infieles (para no decir corrompidas), y más alejadas de la norma de la Biblia y la voluntad de Cristo. ¿Quién no lo reconoce en la Iglesia Católica Romana, la Luterana y la Anglicana? (Hoover, 1984, p. 103)

La infidelidad de las iglesias anteriores se refleja en doctrina y en práctica. En cuanto a lo segundo, Hoover (1984, p. 104) destaca prácticas reprochables moralmente como la asistencia al teatro, el beber alcohol, fumar, jugar cartas y bailar. Pero esto es una expresión, una "manifestación" inversa a las manifestaciones del Espíritu, que es fruto de esta infidelidad elemental, la incredulidad en el peso normativo de la Biblia. En el campo doctrinal, insistió en el hecho de que

En cuanto a la doctrina algunas Iglesias evangélicas, en sus escuelas y seminarios enseñan la Biblia, sí, pero enseñan que no es verdad lo que dice. Enseñan que la historia de la creación es un cuento y no es verdad; que el pez no podía haber tragado a Jonás; que no hay tales ángeles; que la luz que Saulo vio camino a Damasco era relámpago; que la voz que él oyó era de su conciencia y no la de Jesús; que la resurrección de Jesús era espiritual y no física, y muchas otras cosas por el estilo, como que los evangelios son los pensamientos de los que los escribieron y no la vedad de las cosas (Hoover, 1984, p. 103)

¿Qué lugar ve Hoover que juega el pentecostalismo en esta gran contienda teológica entre liberalismo y ortodoxia? Él no escatima palabras para señalar a la experiencia pentecostal chilena como un movimiento "providencial", pues: "Dios usó esa contradicción para contrarrestar la corriente de incredulidad, de infidelidad, y de negación que ha inundado la generalidad de las iglesias evangélicas (de tal modo que en mucho grado han perdido moralmente su derecho de ser llamadas iglesias cristianas)" (Hoover, 1984, p. 91). Esta concepción particular del desarrollo histórico del cristianismo y en especial del protestantismo, tendrá repercusiones relevantes en el modo en que Hoover concebía la relación con aquellas iglesias atravesadas por el pensamiento liberal. En sus términos, 
De aquí el motivo de la existencia de la iglesia pentecostal; y de aquí, también su intransigencia y su completo aislamiento de otras iglesias. La más mínima unión con ellas obra daño a ella. Porque el roce, las conversaciones, la amistad con los que patrocinan tales errores (aunque no los tengan personalmente) tiende a abrir el corazón para oír, discutir o por fin consentir, poco a poco esos errores. Porque esa gente son gente buena, amable, culta, de altos ideales, muy social y por lo mismo, más peligrosa. A la manera de la serpiente en Edén, interpretan, raciocinan, preguntan "¿Conque Dios ha dicho?" y comienzan a minar la fe de los sencillos en la divina autoridad de las Santas Escrituras (Hoover, 1984, p. 92)

Hoover comprendía que el pentecostalismo con su renovación espiritual no consistía solo en vivir experiencias carismáticas, sino que también en ser custodio de una teología ortodoxa. Y la custodia de esta visión tradicional no se entendía como una cuestión de índole intelectual sino ante todo una del campo de la fe. En otros términos, es gracias a la creencia en que los hechos milagrosos descritos en la Biblia y la noción de que los milagros confesados por los dogmas cristianos son creíbles, que es posible para los pentecostales creer en la acción milagrosa de Dios en sus propios días. El pastor Hoover (1984) cierra su "relato" de los hechos (así lo llama él) esperando que "despierte hambre y sed en muchos corazones para tener igual inefable don" (p. 94) del Espíritu Santo como el que ellos recibieron en 1909 en Valparaíso. Aquí encontramos la metáfora del hambre y la sed, aplicada a los creyentes que están interesados en recibir la experiencia espiritual que ellos vivieron. Además de las manifestaciones espirituales, el pentecostalismo temprano chileno no puede entenderse sin considerarlo como un custodio del acervo doctrinal de la tradición cristiana. Esto debido a que es finalmente la defensa de los dogmas y la sobrenaturalidad divina que se expresa en ellos lo que le permite a Hoover creer que Dios puede seguir obrando de manera sobrenatural y, en suma, así justificar las manifestaciones del Espíritu Santo. La separación final de pentecostalismo chileno y metodismo fue expresión del choque entre una experiencia espiritual contra un tipo de teología, la liberal.

\section{El padre Hurtado, o la sed de Cristo}

El padre Hurtado, como se le conoce popularmente en Chile, es una figura imprescindible del catolicismo nacional. Abogado, doctor en pedagogía, sacerdote de la Compañía de Jesús, es reconocido sobre todo por su intenso trabajo con la juventud y los pobres de sus días, llegando a fundar el Hogar de Cristo. Estamos ante un intelectual, pero también ante el sacerdote con vocación de servicio social más importante del país.

Así, diez años después de que Hoover escribiera su libro, Hurtado quiso resolver si Chile era un país católico o no en pleno curso de la II Guerra Mundial. La obra, como es esperable, no estuvo libre de reacciones polémicas privadas y públicas, por acusar en él un pesimismo (Fernández, 2018). Inició diagnosticando que la guerra no solo era material, sino que aún mas destructora es la "guerra espiritual: el choque de ideologías" (Hurtado Cruchaga, 2018, p. 75), con el comunismo soviético y el nazismo haciendo estragos, y con una situación filosófica moderna cuyo que su fondo era "el materialismo agnóstico, el pragmatismo o utilitarismo y el relativismo" (Hurtado Cruchaga, 2018, p. 
76). Con este marco ya definido, el padre Hurtado se avocó a estudiar la situación del catolicismo a nivel mundial y a nivel local sin el deseo de "atenuar sus sombras" ni de "disimular sus defectos". Así, entre las cuestiones que le preocupaban sobre la realidad chilena, el libro contiene un capítulo titulado "La campaña protestante en Chile", en el cual se presenta en términos generales el problema que ha significado el avance evangélico en los sectores populares del país desde una perspectiva católica. En lo sucesivo, exploraremos este capítulo para ver cómo el padre Hurtado relata la situación evangélica en Chile.

La hipótesis nuestra es que el elemento irreductible, la semántica profunda a la que nos remite este texto, es al problema del fervor protestante y sus efectos en relación con el pueblo chileno y el catolicismo. En esta ocasión, será posible observar cómo el autor describe lo que podríamos considerar como una búsqueda de lo divino que trasciende los aspectos religiosos, entendidos estos dos términos según el sentido que les da Meschonnic (2007).

La afirmación de inicio del capítulo es la siguiente: "el protestantismo como religión nacional dondequiera que ha dominado está en franca bancarrota" (Hurtado Cruchaga, 2018, p. 145). Como puede verse, nada auspiciosa. Señala algunas dificultades visibles en Inglaterra y Estados Unidos. Pero es llamativo lo que afirma sobre el caso alemán:

El protestantismo alemán ha caído en gran parte en el racionalismo más fino: con mucha frecuencia, sus jefes niegan la divinidad de Jesucristo. Jesús sería, para ellos, un enviado de Dios, como Hitler. la bancarrota moral del protestantismo oficial es también considerable: los obispos anglicanos, en su reunión de Lambeth aprobaron oficialmente el birth-control, con gran escándalo de los ortodoxos. Todo esto es consecuencia del desorden de ideas que ha introducido el libre examen y de haberse separado de los sarmientos de la verdadera vid (Hurtado Cruchaga, 2018, p. 145)

Más allá de peculiaridades de contexto, el capítulo del padre Hurtado sobre el protestantismo inicia relevando críticamente el hecho del racionalismo propio de la teología liberal y su efecto sobre las creencias cristianas tradicionales. En este punto de arranque, puede decirse con toda seguridad que, en lo que toca a la crítica al protestantismo liberal, Alberto Hurtado estaba en pleno acuerdo con Willis Hoover. La diferencia es que, mientras que Hoover albergaba esperanzas en que el pentecostalismo podría ser un movimiento conservador de la fe tradicional, Hurtado esperaba que los protestantes conscientes del valor de las doctrinas más tradicionales, decepcionados del protestantismo, se integrarían a la Iglesia Católica. En sus términos: "cada vez nos halaga más la esperanza que, en un plazo que está en los secretos de Dios, el protestantismo que persevere cristiano terminará por volver al único redil" (Hoover, 1984, p. 147). Nótese aquí, hay un protestantismo cristiano, y otro que no lo es. Gesto similar hizo Hoover (1984) al señalar que hay iglesias evangélicas "que en mucho grado han perdido moralmente su derecho de ser llamadas iglesias cristianas" (p. 91). 
Las diferencias sustantivas, no obstante, no se harán esperar. El padre Hurtado reconocía por esos años la acción difusora de varias iglesias evangélicas como la metodista, presbiteriana y las diversas ramas pentecostales, y estaba al tanto de la existencia de algunas de sus revistas institucionales como El cristiano, El heraldo evangélico, El fuego de pentecostés, entre varias otras que nombra (Hurtado Cruchaga, 2018, p. 148). Reconocía el "fervor" con que los evangélicos difundían sus ideas e incluso estaba al tanto de que los pentecostales no recibían financiamiento extranjero, sino que costean sus gastos con recursos propios. Asimismo, sabía que había quienes iban de Valparaíso a Quintay a pie para hacer escuela dominical, que también esto se hacía de Valparaíso a Santiago, y que había quienes lo hacían en bicicleta. Destacó en general cualidades como la amabilidad, la servicialidad, el orar durante horas, y que la afiliación a la iglesia suele ser duradera.

La pregunta que preocupa al padre Hurtado en este capítulo es porqué los chilenos de clases populares se hacen protestantes. Un elemento permanente al que recurre para explicar estas conversiones es el hecho de que en Chile el éxito de la "campaña protestante" se debe a "la falta de cultivo religioso de nuestra masa popular. Son ovejas sin pastor, pero con un fondo profundamente cristiano" (Hurtado Cruchaga, 2018, p. 147). El pastor del que carecen es, naturalmente, el sacerdote católico. Aquí el padre desplaza su crítica desde los protestantes a los católicos, pues los chilenos

...abrazan muchos el protestantismo, no por alejarse de la Iglesia, sino porque creen acercarse a Cristo. La responsabilidad del éxito de la campaña protestante en Chile es de los católicos, que no han sabido cultivar su Iglesia y de todos aquellos que han desoído la voz divina (Hurtado Cruchaga, 2018, p. 147)

Los sectores populares se hacen protestantes porque no hay agentes católicos que suplan sus necesidades espirituales. Los primeros son los que ofrecen la posibilidad de acercarse a Cristo, y aunque el chileno de la época pudiera negarse a eso, lo cierto es que "Io que lleva a nuestro pueblo a los protestantes es principalmente su sed de vida religiosa, que no la encuentran muchas veces por falta de cultivo" (Hurtado Cruchaga, 2018, p. 151). La metáfora de la sed incorpora el elemento del agua y, de ese modo, se utiliza para vincular al pueblo con los protestantes del siguiente modo:

...es la sed de Cristo que tiene nuestra pobre gente la que las detiene en esa fuente de agua turbia, pero de agua al fin y al cabo donde encuentran al menos el nombre y la doctrina de Jesús y su vida en el evangelio (Hurtado Cruchaga, 2018, p. 151)

El protestantismo ahora es "agua turbia", no es agua limpia. Hay suciedad en él, pero al menos sirve al pueblo para conocer a Jesús. Así y todo, "arrebata las almas a la verdadera Iglesia" (Hurtado Cruchaga, 2018, p. 157). No puede admitir su acción en Chile, como tampoco ve un catolicismo atento para hacerle frente. Entonces, recurre nuevamente a su análisis de inicio: "el protestantismo como movimiento mundial está en franca bancarrota. Lo mejor que queda de él son estos grupos fervientes, que precisamente porque fervientes han salido a misionar y han llegado hasta nosotros" (Hurtado Cruchaga, 2018, p. 157). A diferencia de su punto de partida del capítulo, en este momento del texto el padre Hurtado no puede sino reconocer que no hay un solo tipo de 
protestantismo, sino dos. Uno el liberal, en bancarrota, pero también otro ferviente capaz no solo de misionar sino también disputarle presencia popular al catolicismo.

Son varios los métodos que los protestantes usan para llegar al pueblo, como reunir y crear grupos pequeños de enseñanza bíblica, la narración de "testimonios" y experiencias religiosas, su comportamiento y transmisión de la fe, pero el elemento irreductible de su efectividad es el "fervor" con que misionan. Ese fervor misionero, sumado a la falta de presencia católica y al alma religiosa del pueblo "que está lejos de estar muerta al espíritu cristiano, que tiene hambre de Cristo, del evangelio, que goza con ponerse en contacto con Dios por la oración y que no ha disminuido nada en su amor por la caridad" (Hurtado Cruchaga, 2018, p. 161) hacen al padre Hurtado vislumbrar que "si tuviéramos más apóstoles que evangelizaran nuestro pueblo este sería profundamente católico" (Hurtado Cruchaga, 2018,161).

La preocupación de este avance misionero de los protestantes no fue solo un tema para el padre Hurtado. En 1956, y desde una perspectiva menos pastoral y más sociológica, con datos al haber, el padre Humberto Muñoz sin pretender moderación alguna, ofrecía una visión catastrofista del siguiente tono: "El avance del protestantismo es aterrador. Hay en Chile más de 240.000 protestantes. De 1940 a 1952 han aumentado en un 105\%. De seguir a esa velocidad, dentro de 50 o 60 años todo Chile será protestante" (Muñoz Ramírez, 1956, p. 55). Diez años después de haberse hecho su pregunta el padre Hurtado, todo parecía indicar que la próxima pregunta obligada en unas décadas más iba a ser ¿Por qué Chile se hizo protestante?

Pese a que para el pastor Hoover la razón de este crecimiento sería la acción del Espíritu, no deja de llamar la atención el hecho de que tanto él como el padre Hurtado apelen a la noción de la "vida". Hurtado apela a la idea de una "sed de vida religiosa" popular, y Hoover a la idea del "avivamiento". Esta segunda coincidencia, junto con la crítica que ambos realizan al protestantismo liberal, permite mostrar que, pese a que ambos iban a defender iglesias distintas y rivales, ambos consideraban que existía una relación necesaria entre dogma y lo que podríamos denominar "vida espiritual". La expansión evangélica en Chile para el padre Hurtado puede resumirse en la falta de obreros católicos, el fervor misional protestante en general, y la sed y hambre de Cristo, no saciadas, que tiene el pueblo chileno. En otros términos, la búsqueda de lo divino no puede ser contenida por la gestión religiosa, sino que la desborda.

\section{La sed, el fuego y la vida. Síntesis conclusiva.}

En un recorrido general por ambos textos hemos podido ir notando cómo se construye un imaginario que ahora revisaremos más sintéticamente. Desde luego, la extensión de ambos es diferente debido a que tratan temas distintos. Para Hoover (1984) el libro entero tiene la prioridad de tratar temas protestantes, mientras que para Hurtado se trata solo de un capítulo. Sin embargo, es 
posible encontrar, en ambos, algunos puntos de coincidencia y de diferencia que son de interés no solo por razones teológicas sino por la construcción del imaginario religioso que han hecho.

En términos generales, se observa que los dos detectan una diferencia teológica fundamental al interior del protestantismo, identificando y criticando una tendencia liberal que se caracteriza por una negación de creencias fundamentales, como la divinidad de Jesús la cual ambos mencionan; e identificando otra que no niega estas creencias. Hoover (1984) se identifica con esta última, mientras que Hurtado, si bien reconoce en ella un fervor misional que incluso llama a imitar, no puede sino criticarla por ser protestante o más bien, por no ser católica.

No obstante, no es el nivel teológico, en cuanto racionalizado, en el que ellos desarrollan su evaluación de los problemas que tratan. La "imaginación poética" en ellos resulta eficaz para elaborar una interpretación del protestantismo que permite situarlo ya no solo en un plano teológico sino en uno existencial.

En primer lugar, ambos comparten una evaluación metafórica en el plano de lo sagrado y lo profano. Willis Hoover recurre a la metáfora de lo puro y lo impuro. El protestantismo incrédulo, liberal, representa la impureza, mientras que el que cree tanto en el dogma como en las manifestaciones espirituales, es puro. Alberto Hurtado, por su parte, utiliza la imagen del "agua turbia" para referirse al protestantismo en general, y su opuesto como "agua limpia" es naturalmente el catolicismo. Podríamos plasmarlo, tal como se ve en la Tabla 1:

Tabla 1

\begin{tabular}{ll|l|} 
& Hoover & Hurtado \\
\cline { 1 - 3 } Pureza / agua limpia & Pentecostalismo & Catolicismo \\
\hline Impureza / agua turbia & Protestantismo liberal & Protestantismo en general \\
\hline \multicolumn{2}{c}{ (Fuente: elaboración propia) }
\end{tabular}

En segundo lugar, en ambos casos se utiliza la metáfora alimentaria del "hambre y la sed". Se trata de necesidades naturales, vitales, por lo cual el elemento religioso aquí refiere a la imposibilidad de la existencia sin comida y sin agua. En el caso de Alberto Hurtado, esto está en directa relación con la metáfora del agua, que implica necesariamente la "sed" religiosa de los sectores populares. En el caso de Hoover (1984), la metáfora del hambre y la sed aparece, pero no referida a la necesidad de un cultivo religioso cualquiera, sino específicamente a la experiencia espiritual. Alberto Hurtado presenta al pueblo chileno como hambriento y sediento de religiosidad, como algo propio de él. Willis Hoover (1984), por el contrario, señala que esta hambre y sed por una experiencia espiritual ha de ser despertada, no está activa. Esto puede sintetizarse así, como lo lo muestra la Tabla 2. 
Tabla 2

\begin{tabular}{lll|l|} 
Hambreysed & \multicolumn{2}{l}{ Hoover } \\
Activa/pasiva & Pasiva: provocada por el & Activa: es propia del pueblo chileno \\
& testimonio espiritual de otros & \\
Sujeto & Principalmente protestantes & Los chilenos en general \\
Objeto & La experiencia del Espíritu Santo & La necesidad de Cristo, de cultivo de vida \\
& & religiosa en general \\
\hline
\end{tabular}

En tercer lugar, pueden encontrarse las alusiones a lenguaje religioso más general en el marco del cristianismo, y que refieren a figuras bíblicas. Hoover, por ejemplo, al referirse al avivamiento usualmente habla del "fuego", refiriéndose con ello a la acción del Espíritu Santo, cuya manifestación en Pentecostés fue la de las "lenguas de fuego" según se registra en la Biblia (Hch 2). Por su parte, Hurtado recurre a la imagen de las "ovejas sin pastor", propia también de la Biblia, presente en los dos testamentos (Sal 23; Jn 10).

En cuarto lugar, es relevante señalar el énfasis que hace Hurtado al "fervor" protestante. Esta es una característica de importancia para él, pues es lo que les permite llegar a los sectores populares descuidados por el catolicismo. Lo que Hurtado no atiende es que, en el caso pentecostal, este fervor viene dado por la experiencia espiritual y, en tal sentido, podría ser que lo que él interpreta como la razón del avance protestante, para el caso pentecostal no sea sino una consecuencia de una experiencia espiritual más profunda, suprarreligiosa, es decir, divina. Cabe añadir que, aunque en la revisión del libro de Hoover no revisamos este punto, lo cierto es que muy ocasionalmente él también utiliza el término "fervor" señalando esta cualidad pentecostal como consecuencia de la experiencia espiritual (Hoover, 1984, pp. 41, 48).

En la superficie, es claro que para ambos autores se está ante contiendas institucionales y teológicas, religiosas en general, relativas a la gestión de lo divino. A Hurtado le preocupa el avance de las iglesias protestantes y su teología no católica, y a Hoover (1984) le preocupa la incredulidad dentro de las instituciones protestantes y su teología no tradicional. No obstante, al revisar el uso del lenguaje de ambos autores, es posible constatar que estos problemas no tienen una dimensión exclusivamente religiosa, sino que remiten al nivel más complejo de lo divino, que corresponde al elemento irreductible de la experiencia trascendente.

Así, desde un enfoque de la semántica profunda, lo que se deja ver gracias al lenguaje metafórico, es que para ambos lo que está en juego va más allá de la superficie teológicoinstitucional, y es el problema de lo que hemos llamado "vida espiritual". El hambre y la sed son instintos vitales de los seres vivos, que les permiten mantenerse con vida. Los sectores populares 
chilenos van al protestantismo por este instinto, aun cuando sea "agua turbia", porque lo primero es suplir la necesidad vital de estar en contacto con lo divino. No se busca lo mejor, sino lo imprescindible. Los pentecostales por su parte, buscan la experiencia del Espíritu porque ella sacia la necesidad vital de estar en contacto con lo trascendente. La pregunta que subyace, tras ambos ensayos, es si acaso el protestantismo puede proveer la alimentación necesaria para la vida espiritual del pueblo o no. Para Hoover (1984) la respuesta es desde luego afirmativa y para Alberto Hurtado, con pesar, y aunque no le parece la mejor dieta, también.

Como puede advertirse, en ambos casos, lo institucional-teológico queda en segundo lugar si se lo considera a la luz de la necesidad vital de espiritualidad, que viene a constituirse la preocupación principal. Los sectores populares irán al protestantismo, reconoce Hurtado, no porque quieran alejarse de la Iglesia -la institución, el credo- sino porque buscan saciar su "sed de Cristo". Los pentecostales se separarán de la Iglesia Metodista -la institución, la teología liberal-, reconoce Hoover (1984), no porque el pentecostalismo deseara ser una innovación, sino porque quiso recuperar una experiencia de fe que consideraba perdida. En una dimensión existencial, y gracias al uso del lenguaje metafórico de ambos, es posible decir que tanto Hoover como Hurtado estuvieron de acuerdo en que cierta forma de protestantismo ofrece una respuesta existencial de "vida espiritual", de acceso a lo divino, que ni la Iglesia Católica ni el protestantismo liberal ofrecían de modo suficiente. En tal sentido, y retomando a Harold Bloom (2009), estamos aquí ante una rebelión contra la muerte, el elemento irreductible más profundo de la religión. Y aunque no se trate aquí de la muerte en un sentido físico, si se trata de ella en un sentido espiritual. El pueblo que se acerca a los protestantes lo hace buscando vida, se rebela contra la falta de agua católica y busca sediento otra fuente de la cual beber. El creyente pentecostal, llevado por la búsqueda de avivamiento, se separa del protestantismo liberal rebelándose contra la mortandad espiritual que percibe en ese sector. Esta sed y esta hambre no permite a los creyentes esperar a que las instituciones religiosas y la teología formal lleguen en su ayuda, se trata de un impulso de sobrevivencia espiritual. La rebelión contra la muerte muestra que lo elemental no es pertenecer a una institución religiosa, sino estar cerca de lo divino.

La diferencia irreconciliable, entre Hoover y Hurtado, es que uno iba a esforzarse por ofrecer la pureza de la experiencia del fuego pentecostal, y el otro el agua limpia del catolicismo. Pese a todo, no dejará nunca de sorprender la paradoja de que un segmento no menor de la población chilena ha optado en el pasado, y aun hasta hoy, por apagar su sed de Cristo con fuego del Espíritu.

\section{Referencias Bibliográficas}

Bloom, H. (2009). La religión americana (D. Alou, Trad.). Buenos Aires: Taurus.

Croatto, J. S. (2002). Las formas del lenguaje de la religión. En F. Diez de Velasco y F. García Bazán (Eds.), El estudio de la religión (pp. 61-99). Madrid: Trotta. 
Dayton, D. W. (2008). Raíces teológicas del pentecostalismo (E. R. De Powell, Trad.). Grand Rapids, MI: Libros Desafío.

Fernández, S. (2018). Introducción. In A. Hurtado Cruchaga S.J. (Autor), ¿Es Chile un país católico? (pp. 15-18). Santiago: Universidad Alberto Hurtado.

Giraud, P. (1972) La semiología (M. T. Poyrazian, Trad.). México D.F.: Siglo XXI.

García Gómez-Heras, J. M. (1972). Teología protestante: sistema e historia. Madrid: Biblioteca de autores cristianos-

Hoover, W. C. (1984). Historia del Avivamiento Pentecostal en Chile. Santiago: Comunidad Teológica Evangélica de Chile.

Hurtado Cruchaga, A. (2018). ¿Es Chile un país católico? Santiago: Universidad Alberto Hurtado.

Klein, I. (2007). La narración. Buenos Aires: Eudeba.

Lalive d'Epinay, C. (2009). El refugio de las masas: estudio sociológico del protestantismo chileno. Santiago: Instituto de Estudios Avanzados.

Machen, J. G. (2013). Cristianismo y liberalismo. San José: CLIR

Mansilla, M. A. (2009). Pentecostalismo y Ciencias Sociales. Reflexión en torno a las investigaciones del pentecostalismo chileno (1968- 2008). Revista Cultura \& Religión, 3(2), 21-42. https://bit.ly/3EZN45g

Meschonnic, H. (2007). Un golpe bíblico en la filosofía. Buenos Aires: Lilmod.

Muñoz Ramírez, H. (1956). Sociología religiosa. Santiago: Paulinas. https://bit.ly/3n00cRK

Orellana Urtubia, L. (2006). El fuego y la nieve: historia del movimiento pentecostal en Chile, 1909-1932 (Vol. 1). Concepción: CEEP. https://bit.ly/3km7gGF

Ricœur, P. (2011) Teoría de la interpretación: discurso y excedente de sentido. México D.F.: Siglo XXI

Rivera Letelier, H. (2006). Himno del ángel parado en una pata. Santiago: Planeta.

Sepúlveda González, J. (1999). De peregrinos a ciudadanos. Breve historia del cristianismo evangélico en Chile. Santiago: Konrad Adenauer Stiftung.

Snow B., F. (1999). Historiografía de la Iglesia Metodista de Chile 1878-1918. Concepción: Ediciones Metodistas.

Vergara Tagle, I. (1962). El protestantismo en Chile. Santiago: del Pacífico.

\section{Para citar este artículo bajo norma APA 7a ed.}

Aránguiz Kahn, L. R. (2021). La sed, el fuego y la vida: una hermenéutica del protestantismo a través de Willis Hoover y Alberto

Hurtado. Cuadernos de teología - Universidad Católica del Norte (En línea), 13, e4761. https://doi.org/10.22199/issn.0719-8175-2021-4761 